Komunike, Volume XII, No. 2 Desember 2020

\title{
CITRA SANTRI PESANTREN DALAM CUPLIKAN FILM THE SANTRI
}

\author{
Mansur Hidayat \\ Institut Agama Islam Negeri Kudus \\ mansurhidayat.id@gmail.com
}

\begin{abstract}
The appearance of the trailer for The Santri movie has sparked various responses on the internet, this can be observed from the existence of parties who are pro and contra with the movie trailer. This difference can be seen from the way the audience responds to and interpret the contents of the movie trailer. This study can understand the image of the student at Islamic Boarding School in the movie trailer of The Santri which can be seen through the account NU Channel on YouTube. The study used a descriptive qualitative approach model with content analysis on movie trailers. The results of the study show that the image of the student at an Islamic Boarding School in the movie trailer of The Santri can be divided into two parts, namely: first, an explicit image such as students must have self-confidence, have high dreams, love religion and their nation, have a good faith, and be a loyal friend. Second, implicit images such as students who have a simple, tough, and brave image, accept differences, and are open-minded.
\end{abstract}

Keywords: Student, Islamic Boarding School, Movie, The Santri, YouTube 
Komunike, Volume XII, No. 2 Desember 2020

\begin{abstract}
Abstrak
Kemunculan cuplikan (trailer) film The Santri telah memantik respon yang amat beragam di internet, hal tersebut dapat diamati dari adanya pihakpihak yang pro maupun yang kontra dengan cuplikan film. Perbedaan tersebut seperti terlihat dari sikap audiens dalam merespon serta memaknai isi dari cuplikan film. Kajian ini dimaksudkan untuk memahami citra santri pesantren dalam cuplikan film The Santri yang ditayangkan melalui YouTube NU Channel. Studi menggunakan model pendekatan kualitatif deskriptif dengan analisis isi pada cuplikan film. Hasil kajian menunjukkan bahwa citra santri pesantren dalam cuplikan film The Santri dapat dibedakan ke dalam dua bagian, yakni: pertama, citra yang tersurat (manifest) seperti santri yang mempunyai rasa percaya diri yang bagus, memiliki cita-cita yang tinggi, mencintai agama dan bangsanya, memiliki keimanan yang baik, serta setia kawan. Kedua, citra yang tersirat (latent message) seperti santri yang dikesankan sederhana dan bersahaja, tangguh nan pemberani, menerima perbedaan, dan memiliki pemikiran yang terbuka terhadap dunia luar (modern).
\end{abstract}

Kata Kunci: Santri, Pesantren, Film, The Santri, YouTube 
Komunike, Volume XII, No. 2 Desember 2020

\section{A. PENDAHULUAN}

Komunikasi

merupakan kegiatan yang tidak dapat lepas dari sebuah proses. Proses yang mencakup sumber, pesan, dan penerima pesan. Ketika terjadi interaksi antara media dengan audiens, maka proses penerimaan pesan tersebut sedang berlangsung. Hal yang cukup penting dimaknai dari proses ini yakni berkaitan dengan penciptaan dan pemahaman terhadap pesan. Pemaknaan yang dimaksud dapat diartikan sebagai pemberian suatu gagasan berkaitan dengan ide-ide yang disampaikan melalui ruang media.

Seiring dengan perkembangan teknologi media, maka proses pemaknaan terhadap pesan yang disirkulasikan melalui ruang media perlu disesuaikan dengan media yang digunakan (Nugroho Rama; Wahyono, S. Bayu 232). Sebab, teknologi telah mengubah cara pandang manusia dalam menyampaikan pesan (Stemler 1).

Berkaitan dengan penyampaian pesan di ruang media, pengamatan pesan juga dapat dilakukan atas tayangan cuplikan (trailer) film The
Santri yang disiarkan melalui YouTube. Di mana, saat ini YouTube telah menjadi situs dengan jumlah kunjungan terbesar kedua dalam peringkatnya secara global setelah Google (Alexa). Atas dasar tersebut, maka YouTube dapat dipertimbangan dalam upaya penyampaian pesan kepada audiens melalui sebuah tayangan cuplikan film.

Cuplikan film umumnya berisikan alur cerita sebuah film yang disusun dengan sangat padat sehingga mampu memberikan daya tarik kepada audiens secara maksimal. Cuplikan film telah menjadi bagian iklan yang disajikan dengan amat halus, bahkan film dengan kualitas kurang sekalipun dapat ditampilkan dengan amat menarik. Bagian-bagian pada cuplikan biasanya memuat adegan-adegan dalam film yang dipromosikan, walaupun terkadang juga berisi adegan yang dipotong sehingga tidak ditampilkan pada film yang dirilis kemudian. Mengenai tujuan utama dibuatnya cuplikan film adalah agar penonton tertarik dengan film serta dapat terlibat secara emosional (Marich 6-42). 
Komunike, Volume XII, No. 2 Desember 2020

Berdasarkan pada pemaparan kiai Said Aqil Siraj dalam konferensi pers film The Santri, kiai Said menjelaskan bahwa NU Channel ${ }^{1}$ yang berada di bawah organisasi Islam PBNU ${ }^{2}$ akan segera merilis film dengan judul "The Santri". Film ini dimaksudkan untuk mempopulerkan santri di kancah global dan dalam negeri. Ia memaparkan bahwa santri berasal dari kata sastra-sastri, yang memiliki makna "orang yang berbudi luhur" sebagaimana telah disampaikan oleh seorang beragama Hindu yang bernama Ki Darmawangsyah. Ki Darmawang syah adalah seorang yang memiliki padepokan di Singosari pada masa kerajaan Airlangga. Kemudian setelah datang agama Islam, istilah sastra-sastri berubah menjadi "santri" yang pada dasarnya adalah orang-orang yang beriman kepada

\footnotetext{
${ }^{1} \mathrm{NU}$ Channel merupakan saluran televise resmi yang dimiliki PBNU. Wadah ini memiliki visi dan misi menjaga kedaulatan Negara Kesatuan Republik Indonesia dengan fokus pada konten yang factual, mendidik dan informative, serta memperkenalkan wajah Islam Nusantara yang rahmatan lil 'alamin. Lihat: (NU Channel, NU Channel TV: Home).

2 PBNU adalah singkatan dari Pengurus Besar Nahdlatul Ulama yang secara formal membawahi semua organisasi yang
}

Allah serta berakhlak mulia dan berbudi pekerti luhur.

Oleh karena itu, cuplikan film The Santri dimaksudkan untuk menjadi media dakwah dengan muatan konten pendidikan budaya, memperkuat kepribadian sebagai manusia yang beragama, berakhlak, serta memiliki integritas yang baik. Adapun segmentasi utama film ditujukan kepada generasi milenial. Selain itu, film tersebut dimaksudkan sebagai sarana untuk memperkuat dan memperkokoh Islam Nusantara sebagai ciri khas dari Islam yang menyatu dengan budaya sebagaimana representasi Islam di Indonesia (NU Channel, "Press Conference Official Trailer Film 'The Santri' Bersama K.H. Said Aqil Siroj”). Berdasarkan pada argumentasi tersebut, santri yang dikemas dalam cuplikan film The Santri dipandang dapat

berafiliasi dengan Nahdlatul Ulama (NU). NU merupakan organisasi masyarakat Islam terbesar di Indonesia saat ini. Dalam rilis data yang dikeluarkan oleh Indonesia Muslim Report 2019, NU memiliki tingkat kepopuleran sebanyak 97,5 persen dan dikenal di semua level generasi. Ditambah, banyak ulama yang terafiliasi dengan ormas ini mempunyai tingkat kepopuleran yang juga amat tinggi di masyarakat, termasuk kiai Said Aqil Siraj sebagai ketua umum PBNU 2010-2020. Lihat: (Ali et al. 11-17). 
merepresentasikan citra santri pesantren sebagaimana tujuan serta maksud akan segera dirilisnya film.

Pada saluran NU Channel di YouTube, sebagaimana awal mula cuplikan film ini ditayangkan, bahwa cuplikan film The Santri telah menjadi video terpopuler kedua di NU Channel. Cuplikan film tersebut telah ditayangkan sebanyak 3,9 juta kali sejak awal penayangannya, yakni sejak 9 September 2019 (NU Channel, "YouTube NU Channel").

$$
\text { Walakin, sejak awal }
$$
penayangannya tersebut, cuplikan film ini telah memunculkan beragam tanggapan dari audiens sekalipun film resminya belum ditayangkan. Respon tersebut dapat diamati dari beberapa unggahan video di YouTube serta beragam komentar di Twitter yang dialamatkan pada cuplikan film. Banyak tanggapan setuju disampaikan terhadap cuplikan film tersebut. Pun, respon kontra juga banyak ditujukan pada cuplikan film. Santri pesantren yang divisualisasikan dalam cuplikan film The Santri telah memunculkan penafsiran yang amat beragam di masyarakat luas. Oleh sebab itu, penelitian ini diperlukan untuk menjawab mengenai bagaimana sebetulnya citra santri pesantren dalam cuplikan film The Santri yang ditayangkan di YouTube.

\section{B. TINJAUAN PUSTAKA}

Penelitian terkait dengan kata kunci santri yang disandingkan dengan film atau cuplikan film masih amat minim dilakukan. Beberapa penelitian yang mengulas tentang santri dengan film antara lain seperti: pertama, "Representasi Identitas Santri (Analisis Semiotika Model John Fiske dalam Film Cahaya Cinta Pesantren)" (Salas Tina 57). Artikel tersebut merupakan tulisan dari Hagi Julio Salas dan Tina Kartika yang mengulas tentang representasi identitas santri yang terdapat pada film Cahaya Cinta Pesantren yang diangkat dari novel yang ditulis oleh Ira Madan. Pengamatan yang dilakukan oleh penulis dalam penelitian ini terbatas pada kajian semiotik atau kajian mengenai tanda menggunakan pola analisis dari John Fiske (Salas Tina 60-62).

Kedua, penelitian dari Bakhita Aida dan Hapsari Dwiningtyas dengan judul "Pemaknaan Santri 
Komunike, Volume XII, No. 2 Desember 2020

Mengenai Wacana Poligami pada Film Surga yang Tak Dirindukan 2”. Artikel ini mengulas tentang pemaknaan santri mengenai wacana poligami dalam film Surga yang Tak Dirindukan 2. Analisis yang digunakan dalam objek kajian menggunakan teori encodingdecoding dan teori nurture (Dwiningtyas Sulityani Bakhita 14).

Ketiga, artikel yang berjudul "Analisis Semiotik Charles Sanders Pierce pada Trailer Film The Santri" yang ditulis oleh Aini Fitriyah. Di mana penulisnya lebih menekankan objek kajiannya pada sisi semiotik dengan menggunakan model analisis yang digagas oleh Charles Sanders Pierce (Fitriyah 58-61).

Ketiga penelitian tersebut di atas merupakan jenis penelitian kualitatif sebagaimana metode tersebut juga digunakan pada kajian citra santri pesantren dalam cuplikan film The Santri. Akan tetapi terdapat perbedaan mendasar antara penelitian sebelumnya dengan kajian pada artikel ini, utamanya terletak pada alat yang digunakan dalam menganalisisnya. Sehingga, hasil yang diperoleh dengan metode analisis yang berbeda dapat memunculkan pemaknaan yang berbeda yang belum terbahas dari penelitian-penelitian sebelumnya.

\section{METODE PENELITIAN}

Model penelitian dalam kajian ini menggunakan metode kualitatif deskriptif dengan fokus pada analisis isi terhadap citra santri pesantren dalam cuplikan film The Santri. Analisis isi (content analysis) adalah metode penelitian yang umum dimanfaatkan untuk mengidentifikasi isi pesan yang disampaikan dalam sebuah komunikasi (Ahmad 1). Penggunaan metode ini telah sekian lama berlangsung, yakni sejak 4.000 tahun sejak masa Romawi kuno. Dalam penelitian kualitatif, analisis isi digunakan dalam menganalisis dan menafsirkan suatu teks.

Cara menganalisis semacam ini dimaksudkan untuk mengupas objek yang dianalisis secara berimbang sehingga diperoleh gambaran dari isi pesan dengan apa adanya dan benar-benar menggambarkan isi dari suatu objek yang dianalisis tanpa keberpihakan dari peneliti. Penggunaan analisis 
model ini dimaksudkan agar suatu riset penelitian jauh dari bias dan kecenderungan-kecenderungan

subjektif lainnya (Ahmad 2-5). Sehingga model analisis dapat menjadi semacam bahasa yang digunakan untuk sebuah penelitian dengan tingkat objektivitas, validitas, dan reabilitas yang baik (Hendriyani 64).

Adapun data yang diamati dalam analisis isi ini tidak hanya terbatas pada data tekstual semata, walakin meliputi data visual seperti halnya foto atau video dan juga data dalam bentuk audio (Stemler 1). Pada aplikasinya yakni: pertama, bentuk analisis tekstual meliputi analisis pada beberapa teks (tulisan) yang ditampilkan secara langsung dalam cuplikan film The Santri seperti halnya tulisan dream, faith, friendship, the santri, dan seterusnya.

Kedua, analisis pada foto atau video, yakni analisis pada video yang berjalan dengan tangkapan layar (screenshot) pada beberapa bagian inti dalam cuplikan film, seperti halnya tangkapan layar pada tampilan menit pertama cuplikan film, gambar santri putra dan putri yang sedang berjalan bersisian, frog angle pada bakiak santri putra dan putri, tampilan guru yang berada di tengah-tengah santri, para santri yang tengah naik gerobak sapi, pemberian buku dan tasbih oleh santri putra kepada santri putri, dan lain sebagainya.

Ketiga, analisis pada audio dalam cuplikan film, yakni analisis pada bunyi-bunyi alat musik, narasi yang disampaikan oleh narator, suarasuara dari para aktor, dan semisalnya.

Selanjutnya, analisis isi tersebut dikerucutkan pada bentuk komunikasi yang tampak atau tersurat (manifest) dan yang tersembunyi atau tersirat (latent message) (Sartika 6669).

Berkenaan dengan pengamatan pada citra santri pesantren dalam cuplikan film The Santri, maka bentuk dari komunikasi tersebut dapat dibagi ke dalam dua bagianl, yakni: pertama, citra santri yang tampak (manifest), sebagaimana ditunjukkan dari suara narator yang membawakan cerita, ditampilkannya bendera merah putih pada menit awal pembuka, serta teks yang ditampilkan secara berurutan dalam cuplikan film. 
Komunike, Volume XII, No. 2 Desember 2020

Kedua, citra santri yang ditampilkan secara tersirat (latent message) dengan penyelidikan pada angle kamera, busana yang dikenakan, serta beberapa adegan yang ditampilkan dalam cuplikan film.

\section{HASIL DAN PEMBAHASAN}

Secara umum, dalam deskripsinya Clifford Geertz, istilah santi dapat dimaknai orang Islam yang memiliki pemahaman yang kuat dalam agama dan menjalankan ajaran agama secara konsisten (Mustaqim 336-38). Sedangkan secara khusus, santri dalam uraiannya Ziemek, berasal dari kata sant dan tri. Sant berarti 'manusia baik', dan tri mengandung maksud 'suka menolong'. Jadi, santri adalah manusia baik-baik yang suka menolong (Hidayat, "Model Komunikasi Kyai Dengan Santri Di Pesantren"). Adapun pesantren adalah asrama tempat bagi para santri belajar mengaji dan sebagainya (Kamus Besar Bahasa Indonesia).

Santri merupakan bagian yang tidak dapat dipisahkan dari keberadaan pesantren itu sendiri.

Tujuan dari adanya pesantren memiliki maksud yang antara lain: mengangkat moral, mempertinggi dan melatih semangat, menghargai nilai spiritual dan kemanusiaan, mengajarkan tentang perilaku jujur dan bermoral, serta mempersiapkan santri agar hidup dengan sederhana dan senantiasa memiliki hati yang bersih (Hidayat, "Model Komunikasi Kyai Dengan Santri Di Pesantren").

Saat ini, jumlah keseluruhan pesantren di Indonesia tidak kurang dari 26.974 pesantren, dengan total santri sebanyak 4.009.566 orang. Dengan rincian sebanyak 1.443 .803 orang adalah santri mukim dan 2.565.763 orang merupakan santri non-mukim (kalong).

Sedangkan berdasarkan pada tipe pengajarannya, pesantren dapat dibagi ke dalam dua kategori: pertama, pesantren tradisional. Yakni pesantren yang dalam pengajarannya secara khusus menggunakan kitab kuning. Adapun jumlah pesantren dengan tipe ini ada sebanyak 12.668 pesantren. Kedua, pesantren tradisional-modern. Merupakan pesantren yang dalam pengajarannya berbasis pada kitab kuning sekaligus 
memiliki kurikulum formal sekolah atau madrasah. Mengenai jumlah pesantren dengan model ini sebanyak 14.306 pesantren (Agama).

Pesantren merupakan lembaga yang telah berkembang dan bertumbuh serta turut berkontribusi dalam upaya mencerdaskan kehidapan masyarakat Indonesia sejak ratusan tahun yang lalu sebelum Indonesia merdeka (Faisol 37). Bahkan ketika mengkaji sejarah perkembangan Islam di Indonesia, keberadaan pesantren tidak dapat dikesampingkan. Banyak sejarawan berpandangan bahwa awal mula dari pesantren tidak dapat dilepaskan dari peranan dakwah Walisongo di wilayah Jawa. Ahli sejarah mencatat bahwa cikal bakal pesantren bermula dari daerah Ampeldenta di bawah pengasuhan Sunan Ampel pada abad ke-16 Masehi (Muhakamurrohman 111-12).

Setelah itu, baru kemudian berdirilah pesantren-pesantren yang lain disebabkan adanya dorongan kuat dalam diri santri untuk mengamalkan ilmu yang telah mereka pelajari sebelumnya dari Sunan Ampel. Sedangkan model pesantren sebagaimana lazim dikenal saat ini bermula pada abad ke-18. Seperti terdapatnya pesantren Tegalsari Ponorogo yang didirikan pada 1724 Masehi yang tercatat menjadi lembaga pendidikan pesantren tertua di Indonesia.

Berdasarkan hasil survei pemerintah Belanda pada 1819 Masehi, lembaga pesantren telah mengalami perkembangan yang amat pesat, hal ini ditandai dengan adanya pesantren-pesantren yang telah tersebar di tanah Jawa, seperti halnya pesantren di Ponorogo, Madiun, Surabaya, Kedu, Rembang, Pekalongan, dan Priangan (Mustaqim 333-37).

\section{Santri dan Nahdlatul Ulama}

Santri merupakan sosok yang tidak dapat dipisahkan dari terminologi pesantren dan organisasi besar Nahdlatul Ulama. Bahkan dalam perkembangannya, sebutan santri kerap kali dilekatkan pada golongan nahdliyyin (NU). Melalui istilah santri, baru kemudian muncul istilah pesantren yang dipahami sebagai tempat bagi para santri dalam mendalami ilmu dan menjalani penggemblengan. 
Komunike, Volume XII, No. 2 Desember 2020

Santri dapat diartikan sebagai seorang yang memiliki ketaatan yang luar biasa kuat terhadap kiai atau guru. Ketaatan seorang santri kepada kiai merupakan manifestasi dari sikap beragama yang memberikan penghargaan terhadap orang yang berilmu. Dan, kiai dipandang sebagai sosok yang ahli dalam ilmu agama. Sehingga ketundukan serta ketaatan santri terhadap apa saja yang diperintahkan kiai disebabkan melekatnya nilai kebenaran pada perintah tersebut sebagaimana yang diyakini oleh santri. NU sendiri merupakan organisasi Islam yang basis terbesarnya adalah kaum santri (Mustaqim 336-38).

\section{Segmentasi Audiens Film The Santri}

\section{Segmentasi audiens} berdasarkan keterangan yang telah disampaikan dalam konferensi pers oleh produser eksekutif film tersebut, kiai Said Aqil Siraj, menyatakan bahwa film The Santri dibuat dengan segementasi utama pada kalangan milenial (NU Channel, "Press Conference Official Trailer Film 'The Santri' Bersama K.H. Said Aqil Siroj").
Kalangan milenial sendiri adalah generasi yang lahir pada tahun 1980-an hingga awal 2000-an. Yang cara berpikir, berperilaku, serta pemaknaan atas nilai-nilai mereka banyak dipengaruhi oleh media gawai, internet, dan jejaring sosial, termasuk di antaranya adalah YouTube. Berdasarkan hasil riset IDN Research Institut yang bekerja sama dengan Alvara Research Center bahwa 94,4 persen generasi milenial di Indonesia telah terkoneksi dengan internet serta menempatkan internet sebagai kebutuhan utama (Hidayat, "Model Komunikasi Dakwah Milenial Di YouTube Pada Lagu Aisyah Istri Rasulullah” 268-69).

Atas dasar itulah maka diperlukan pendekatan khusus dalam menarik simpati kelompok milenial. Salah satu cara yakni dengan memanfaatkan media YouTube sebagai salurannnya. Yang dalam hal ini agaknya bersesuaian dengan cuplikan film The Santri yang disiarkan melalui YouTube. 


\section{Alur dan Konten pada Cuplikan}

\section{Film The Santri}

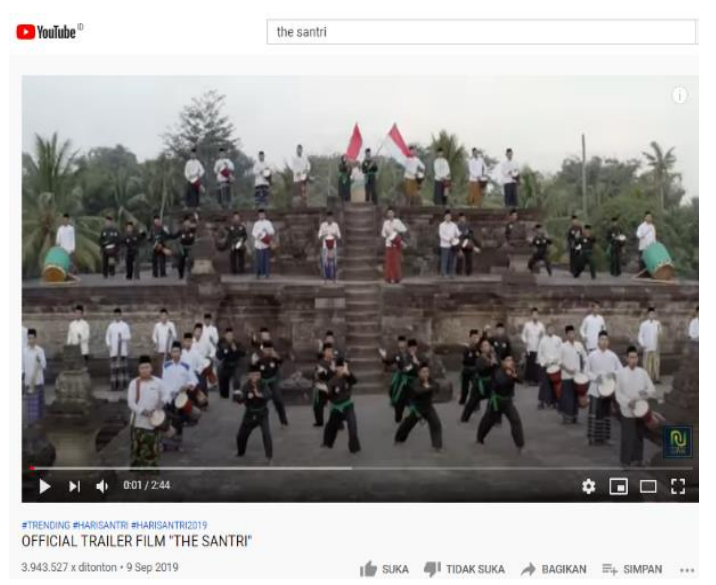

Gambar 1: tampilkan menit pertama dalam cuplikan film The Santri (NU Channel, Official Trailer Film "The Santri” Di YouTube)

Cuplikan film the Santri dibuka dengan adegan latihan silat bersama-sama oleh anggota Pagar Nusa $^{3}$ dengan dibersamai para santri yang tampak memegang dan memainkan alat musik darbuka dan bedug. Selain itu juga terdapat beberapa santri yang memegang bendera merah putih pada bagian tengah atas. Adapun latar belakang yang diambil dalam scene pembuka

\footnotetext{
${ }^{3}$ Pagar Nusa adalah salah satu badan otonom Nahdlatul Ulama yang bertugas menggali, mengembangkan, dan melestarikan bela diri pencak silat Nahdlatul Ulama. Pagar Nusa sendiri adalah singkatan Pagarnya NU dan bangsa. Lihat: (Alawi).

${ }^{4}$ Nama lengkap dari Emil Dardak adalah Emil Elestianto Dardak. Saat ini, Emil adalah wakil Gubernur Jawa Timur periode
}

cuplikan film ini adalah bangunan candi.

$$
\text { Bersamaan dengan tampilan }
$$
tersebut terdapat narasi motivasi sertaan yang kira-kira terdengar sebagaimana berikut:

"reactions, define how you are, so believe in yourself, in belief in your dreams."

Di mana narasi tersebut disampaikan oleh sosok yang ditampilkan seperti sebagai kiai atau guru muda para santri yang diperankan oleh Emil Dardak. ${ }^{4}$

Selanjutnya film dibuka dengan menampilkan logo NU Channel, kemudian dilanjutkan dengan narasi yang juga disampaikan oleh Emil Dardak sebagai berikut:

"Santri, adalah bagian yang tidak dapat dipisahkan, dari perjalanan bangsa Indonesia” (jeda)

"Pada hari santri ini, enam yang terbaik di antara kalian akan terpilih, untuk berangkat dan bekerja di Amerika Serikat.

2019-2024. Setelah sebelumnya ia menjabat sebagai Bupati Trenggalek pada 2016-2019. Ia merupakan cucu dari Haji Mochamad Dardak, seorang kiai Nahdlatul Ulama (NU). Sedangkan ayahnya, Hermanto Dardak, adalah wakil menteri Pekerjaan Umum 20102014. Sementara ibunya, Sri Widayati, adalah keturunan Wiloejo Poespojudo, Gubernur Lemhanas RI pertama. 
Komunike, Volume XII, No. 2 Desember 2020

Buatlah Negaramu dan agamamu bangga!"

(alunan musik)

Narasi tersebut diiringi dengan penampilan para santri putra dan santri putri yang berjalan bersisian sembari masing-masing terlihat memegang kitab kuning tafsir Jalalain di dada. Para santri putra terlihat mengenakan pakaian lengkap santri dengan peci hitam, koko putih, dan sarung. Sedangkan para santri putri berbusana muslimah dengan jilbab dan baju putih yang dipadu dengan sarung. Berikut gambarnya:

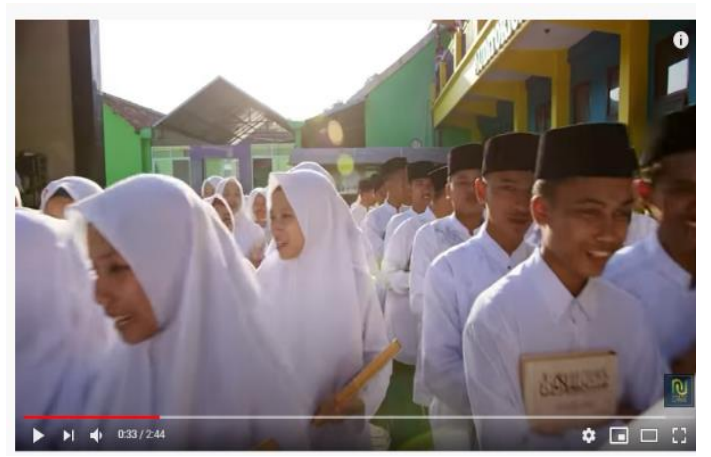

Gambar 2: santri putra dan putri berjalan bersisian (NU Channel, Official Trailer Film "The Santri” Di YouTube)

Selanjutnya, bagian tersebut bersambung dengan scene kamera frog angle ke arah kaki para santri yang berjalan dengan sandal bakiak serta terdengar pula suara bakiak yang tengah dipakai berjalan. Berikut tampilan gambarnya:

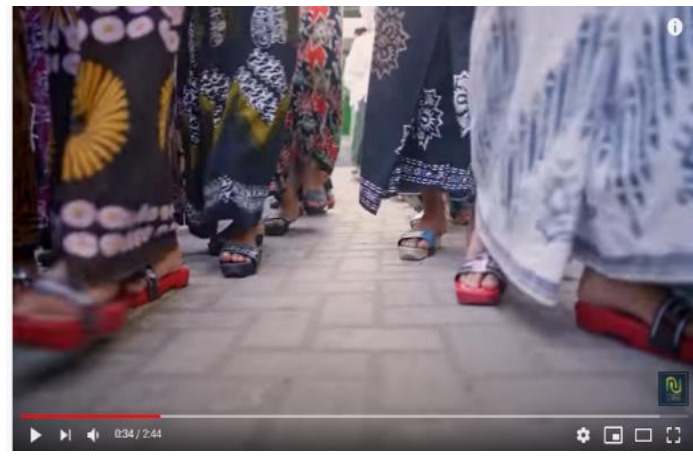

Gambar 3: frog angle pada bakiak santri putra dan putri yang berjalan bersisian (NU Channel, Official Trailer Film "The Santri"

$$
\text { Di YouTube) }
$$

Setelah itu, scene berganti ke tampilan para santri putri yang sedang duduk berada dalam satu majelis. Lalu sorot kamera mengarah pada tampilan sang guru (Emil Dardak) yang sedang berjalan di tengahtengah santri sambil mengucapkan narasi tersebut di atas. Berikut salah salah satu cuplikannya:

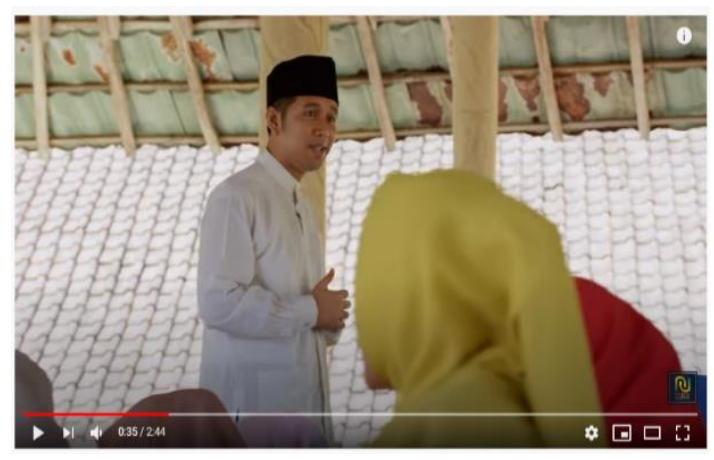

Gambar 4: guru di tengah-tengah santri (NU Channel, Official Trailer Film "The Santri" Di YouTube)

Setelahnya, scene beralih ke suasana asri pedesaan, kemudian pada gerobak sapi lengkap dengan kusir 
Komunike, Volume XII, No. 2 Desember 2020

yang sedang memandu jalannya gerobak yang di belakangnya terdapat tiga santri (Wirda Mansur ${ }^{5}$, Veve Zulfikar $^{6}$, Azmi Askandar $^{7}$ ) dan seorang guru (Emil Dardak) dengan seragam silat Pagar Nusa. Berikut potongan gambarnya:

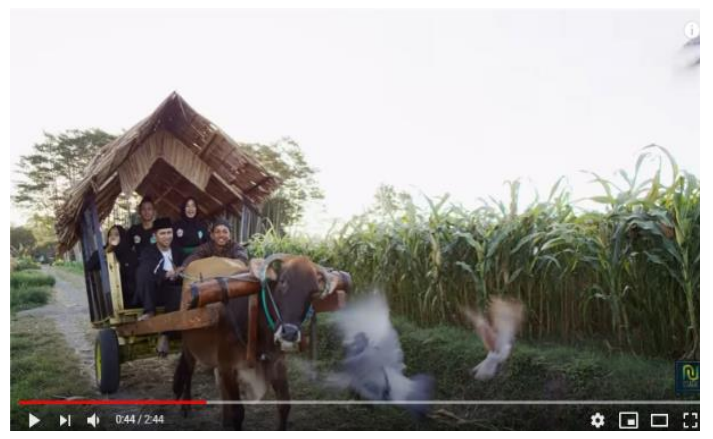

Gambar 5: tiga santri dan seorang guru yang tengah menaiki gerobak sapi dipandu kusir (NU Channel, Official Trailer Film "The Santri" Di YouTube)

Selanjutnya, adegan disambung dengan pertarungan tiga orang yang berada di samping pelabuhan. Setelah itu disambung dengan scene seorang santri putra (Azmi Askandar) yang sedang memencet tombol-tombol laptop yang seolah seperti sedang meretas

${ }^{5}$ Wirda Mansur memiliki nama lengkap Wirda Salamah Ulya Mansur. Wirda lahir pada 29 November 1999. Ia hafal Alquran di usia 14 tahun dan saat ini tercatat sebagai mahasiswa Universitas Oxford. Di kalangan milenial namanya cukup popular (Gresnia Arela Febriani).

${ }^{6}$ Veve Zulfikar adalah nama pendek dari Syarifah Veryal Eisha Aqila Zulfikar Basyaiban. Ia kelahiran Jombang, 7 Juli sebuah situs. Kemudian disambung dengan tampilan seorang tua yang terdengar berucap: "habisi dia!", di depan dua anak buahnya seperti seolah mereka ditampilkan sebagai pemeran antagonis.

Kemudian bersambung scene Wirda Mansur yang sedang berdoa:

"Ya Allah, kabulkanlah doaku untuk bisa melindunginya.."

Narasi tersebut beriringan dengan scene Azmi Askandar yang sedang menaiki kapal tradisional dengan ombak laut yang bergelombang. Lalu scene berpindah ke suasana gereja yang disertai suara lonceng, dan dua orang santri putri yang tengah berjalan masuk ke dalam gereja dengan disertai ucapan dari Wirda Mansur kepada pastur:

"Please, accept define of love!"

Setelah itu, kemudian scene bersambung pada adegan pemberian tasbih dan buku tulis dari seorang

2003. Veve adalah puteri pertama dari lima bersaudara. Kegiatannya yang lain yakni sebagai penyanyi lagu religi (Veve Zulfikar).

${ }^{7}$ Azmi Askandar bernama lengkap Muhammad Ulul Azmi Askandar Al-Abshor yang lahir di Probolinggo pada 23 April 2004. Ia merupakan vokalis dari grup salawat Syubbanul Muslimin dari Pesantren Nurul Qodim Kalijakar Probolinggo. Lihat: (Saintif). 
santri putra (Azmi Askandar) yang berdiri tegak menghadap ke santri putri (Wirda Mansur) yang sedang duduk di atas kuda. Dengan ucapan dari Azmi Askandar:

"Kutitipkan tasbih dan tulisan ini untukmu, agar kamu selalu ingat Tuhan dan diriku."

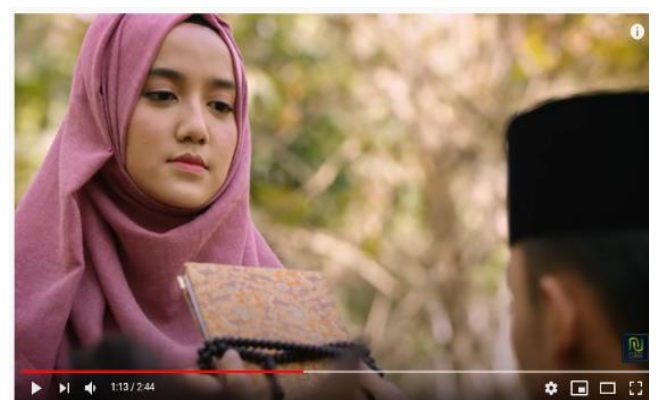

Gambar 6: pemberian buku dan tasbih oleh santri putra kepada santri putri (NU Channel, Official Trailer Film "The Santri” Di YouTube)

Berikutnya, scene berganti ke pesawat yang sedang take off. Lalu zoom out pada Azmi Askandar yang masih berada di tengah hutan. Sesudah itu, shot kamera mengarah ke gedung-gedung pencakar langit di kota New York, Amerika Serikat.

Seterusnya, bagian disambung dengan beberapa kata yang ditampilkan secara beruntun: "DREAM", "FAITH”, dan “FRIENDSHIP". Selanjutnya cuplikan film ditutup dengan menampilkan Patung Liberty di
Amerika Serikat. Lalu

ditampilkan pula tulisan "THE SANTRI", baru kemudian Logo Nahdlatul Ulama.

Setelah cuplikan film usai, kemudian tampil kiai Said Aqil Siroj yang sedang berdiri bersama Livi Zheng di kantor ketua PBNU. Selanjutnya kiai Said memberikan sambutan sebagai berikut:

"Assalamu'alaikum warahmatullahi wabarakatuh.

Saya Said Aqil Siroj, Ketua Umum Nahdlatul Ulama, siang hari ini datang ke kantor saya, seorang sutradara holywood asli blitar jawa timur indonesia. Bernama livi zeng, yang rencananya bersama $N U$ Channel akan membuat film "The Santri!"

Film drama-action yang isinya mengandung nilai-nilai Islam yang santun, toleran, ramah, plural, dan Islam berbudaya, akhlakul karimah, peradaban. Jauh dari Islam radikal, Islam ekstrim, apalagi Islam teror. Islam sebenarnya berasal dari kata salam, shalom, peace, damai.

Mabruk!

Mudah-mudahan Allah memberikan kekuatan lahir dan batin, sukses, berkah, bagi kita semua, wallahul muwaffiq ilaa aqwamithorieq.

Wassalamu'alaikum warahmatullahi wabarakatuh. 
Komunike, Volume XII, No. 2 Desember 2020

Berikut gambar pembuka, sambutan Kiai Said akan penayangan film The Santri. Adapun sambutan tersebut juga disertai subtitle dalam bahasa Inggris.

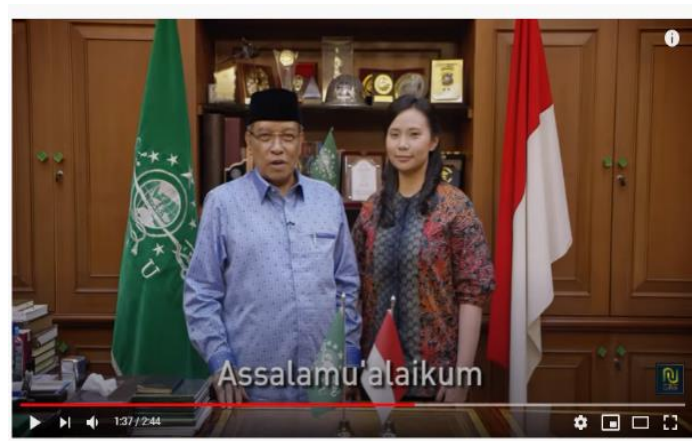

Gambar 7: sambutan kiai Said atas penayangan film The Santri (NU Channel, Official Trailer Film "The Santri" Di YouTube)

Setelah sambutan tersebut, secara berurutan dan teratur ditampilkan beberapa tulisan penutup sebagaimana berikut:

\section{EKSEKUTIF PRODUSER}

KH. SAID AQIL SIRAJ

IMAM PITUDUH

DIRECTED BY

LIVI ZHENG

KEN ZHENG

COMPOSED BY

PURWACARAKA
Adapun total durasi pada cuplikan film The Santri adalah 1 menit 35 detik. Jika digabungkan dengan sambutan kiai Said, maka panjang cuplikan film ini menjadi 2 menit 44 detik.

Dari pemaparan dalam pembahasan tersebut, maka dapat diperoleh gambaran citra santri pesantren dengan membaginya ke dalam dua bagian, yakni citra santri pesantren yang ditunjukkan secara tersurat (manifest) dan citra santri pesantren yang ditampilkan secara tersirat (laten message). Adapun penjelasannya adalah sebagai berikut:

Pertama, citra yang tersurat (manifest), seperti:

a. Santri yang digambarkan sebagai pribadi yang senantiasa mencintai agama dan bangsanya. Hal ini terlihat dari narasi yang disampaikan oleh seorang yang berperan sebagai sosok guru muda dalam cuplikan film tersebut. Citra ini dapat diamati dari potongan narasi ini:

"Santri, adalah bagian yang tidak dapat dipisahkan, dari perjalanan bangsa Indonesia." 
Komunike, Volume XII, No. 2 Desember 2020

Dan narasi: "Buatlah Negaramu dan agamamu bangga!" Serta tampilan bendera merah putih dan juga alur kisah pada cuplikan film.

b. Santri harus memiliki citracita tinggi, keimanan yang baik, serta berjiwa setia kawan. Ini terdengar dari apa yang disampaikan oleh sosok guru dalam cuplikan film pada bagian pembuka: "so believe in yourself, in belief in your dreams." Dan tampilan teks dalam video seperti: "dream”, "faith", dan "friendship".

Kedua, citra santri yang dikesankan secara tersirat (latent message), yakni:

a. Santri dengan citra sederhana. Hal ini terlihat dari busana yang dikenakan oleh para santri dan sorot kamera ke sandal bakiak dengan disertai suara bakiak.

b. Santri harus tangguh dan pemberani. Hal ini dapat diamati dari shot pada beberapa aksi laga dalam latihan silat serta pertarungan.

c. Santri yang mampu menerima perbedaan keyakinan beragama. Seperti terlihat pada adegan penyerahan tumpeng dari dua santri putri kepada pastur di dalam gereja. d. Santri yang memiliki pemikiran terbuka dengan dunia luar (modern). Terlihat dari santri yang terampil menggunakan laptop dan tampilan kota New York serta Patung Liberty.

Sementara untuk memahami kisah percintaan serta unsur budaya santri pesantren yang terdapat dalam cuplikan film, agaknya hal ini sengaja ditampilkan oleh produser dengan alasan bahwa film ditujukan kepada generasi milenial yang lekat dengan sisi romantisme. Adapun sebab yang lainnya bahwa film tersebut bakal ditayangkan secara perdana di lima Negara sebelum pada akhirnya diputar di bioskop-bioskop Indonesia. Hal inilah yang kemungkinan mendasari lekatnya unsur romantisme dalam beberapa shot cuplikan film dikarenakan melakukan penyesuaian pada budaya dan generasi. Sebagaimana dikatakan Champbell bahwa ketika otoritas agama ingin memasuki ruang internet.

Maka suatu pesan yang disampaikan perlu memperhatikan dan menyesuaikan media yang digunakan serta audiens yang dituju (Hidayat, "Sedekah Online Yusuf 
Mansur: Otoritas Dan Bahasa Agama Di Media Sosial" 9). Barangkali demikianlah yang dipahami oleh produser dari film The Santri.

\section{E. KESIMPULAN}

Berdasarkan pada pembahasan di atas, kajian ini menemukan citra santri pesantren dalam cuplikan film The Santri yang antara lain, yakni: pertama, citra santri yang tersurat (manifest) seperti dikesankan santri harus mempunyai rasa percaya diri yang bagus, memiliki cita-cita yang tinggi, pribadi yang mencintai agama dan bangsanya, mempunyai keimanan yang baik, serta setia kepada kawan. Kedua, citra santri yang tersirat (latent message), seperti: santri yang memiliki citra sederhana, tangguh nan pemberani, menerima perbedaan, serta terbuka dengan dunia luar (modern).
Adapun riset dalam artikel ini memang terbatas hanya pada kajian isi cuplikan film semata, sedangkan respon audiens terhadap cuplikan film belum terbahas, sehingga amat memungkinkan untuk dilakukan penelitian pada bagian tersebut. 
Komunike, Volume XII, No. 2 Desember 2020

\section{F. DAFTAR PUSTAKA}

Agama, Kementerian. "Pangkalan Data Pondok Pesantren." Kementerian Agama, 2019, https://ditpdpontren.kemenag.go .id/pdpp/statistik.

Ahmad, Jumal. "Desain Penelitian Analisis Isi (Content Analysis)." Research Gate, vol. 5, 2018, hlm. 1-20.

Alawi, Abdullah. Sejarah Pencak Silat Nahdlatul Ulama Pagar Nusa. 2019, https://www.nu.or.id/post/read/1 07072/sejarah-pencak-silatnahdlatul-ulama-pagar-nusa.

Alexa. Competitive Analysis, Marketing Mix and Traffic: Youtube.Com. 2020, https://www.alexa.com/siteinfo/ youtube.com\#trafficstats.

Ali, Hasanuddin, et al. Indonesia Moslem Report 2019. no. December, 2019, pp. 11-14, www.alvara-strategic.com.

Dwiningtyas Sulityani Bakhita, Hapsari; Aida. "Pemaknaan Santri Mengenai Wacana Poligami Pada Film Surga Yang Tak Dirindukan 2." Interaksi Online, no. Vol 6, No 3: Juli 2018, Jurusan Ilmu Komunikasi, FISIP, Universitas Diponegoro, 2018, pp. 146-57, https://ejournal3.undip.ac.id/ind ex.php/interaksi-

online/article/view/20993/19657

Faisol, M. "Peran Pondok Pesantren Dalam Membina Keberagamaan Santri." Jurnal Al-Tanzim, no. Vol 1, No 2, JURNAL AL-
TANZIM, 2017, hlm. 37-51, https://ejournal.unuja.ac.id/inde x.php/altanzim/article/view/112.

Fitriyah, Aini. "Analisis Semiotik Charles Sanders Pierce Pada Trailer Film The Santri." ATTABSYIR, no. Vol 7, No 1 (2020): Juni 2020, Prodi Komunikasi Penyiaran Islam Fakultas Dakwah dan Komunikasi Islam, 2020, https://journal.iainkudus.ac.id/in dex.php/komunikasi/article/vie w/7150/pdf.

Gresnia Arela Febriani. Kisah Inspiratif Hijabers Milenial Wirda Mansur, Jadi Direktur Di Usia 18. 2020, https://wolipop.detik.com/hijabprofile/d-4999195/kisahinspiratif-hijabers-milenialwirda-mansur-jadi-direktur-diusia-18.

Hendriyani, Hendriyani. "Analisis Isi: Sebuah Pengantar Metodologi Yang Mendalam Dan Kaya Dengan Contoh.' Jurnal Komunikasi Indonesia, 2017, hlm. 63-65.

Hidayat, Mansur. "Model

Komunikasi Dakwah Milenial

Di YouTube Pada Lagu Aisyah Istri Rasulullah." AT-TABSYIR: Jurnal Komunikasi Dan Penyiaran Islam, vol. 7, no. 2, 2020, https://journal.iainkudus.ac.id/in dex.php/komunikasi/article/vie w/8723.

---. "Model Komunikasi Kyai Dengan Santri Di Pesantren." Jurnal ASPIKOM, vol. 2, no. 6, 
Feb. 2016, hlm. 385, doi:10.24329/aspikom.v2i6.89.

---. "Sedekah Online Yusuf Mansur: Otoritas Dan Bahasa Agama Di Media Sosial." Fikrah: Jurnal Ilmu Aqidah Dan Studi Keagamaan, vol. 6, no. 1, 2018.

Kamus Besar Bahasa Indonesia. Pengertian Pesantren. 2020, https://kbbi.kemdikbud.go.id/en tri/pesantren.

Marich, Robert. Marketing to Moviegoers: A Handbook of Strategies and Tactics. SIU Press, 2013.

Muhakamurrohman, Ahmad. "Pesantren: Santri, Kiai, Dan Tradisi." IBDA : Jurnal Kajian Islam Dan Budaya, no. Vol 12 No 2 (2014): Juli 2014, Lembaga Penelitian dan Pengabdian kepada Masyarakat, Institut Agama Islam Negeri Purwokerto, 2014, http://ejournal.iainpurwokerto.a c.id/index.php/ibda/article/view/ 440/395.

Mustaqim, Muhammad. "Politik Kebangsaan Kaum Santri: Studi Atas Kiprah Politik Nahdlatul Ulama." ADDIN, no. Vol 9, No 2 (2015): ADDIN, P3M STAIN Kudus, 2015, http://journal.stainkudus.ac.id/in dex.php/Addin/article/view/618.

NU Channel. NU Channel TV: Home. 2020, http://nuchannel.tv/.

---. Official Trailer Film "The Santri” Di YouTube. 2019, https://www.youtube.com/watch ?v=agbFR_TBxxM.
---. "Press Conference Official Trailer Film 'The Santri' Bersama K.H. Said Aqil Siroj." 2019, 2019, https://www.youtube.com/watch ?v=L_BxZJ46JQc.

---. "YouTube NU Channel." 2020, 2020 , https://www.youtube.com/c/NU CHANNEL/videos?view=0\&so $\mathrm{rt}=\mathrm{p} \&$ flow $=$ grid .

Nugroho Rama; Wahyono, S. Bayu, Heru; Kertamukti. "Komunikasi Visual: Fantasi Tubuh Wanita Kelas Menengah Di Instagram." Jurnal Kajian Komunikasi, no. Vol 6, No 2 (2018): Accredited by Kemenristekdikti RI SK No. 48a/E/KPT/2017, Universitas Padjadjaran, 2018, hlm. 231-46, http://jurnal.unpad.ac.id/jkk/arti cle/view/17925.

Saintif. Biodata Gus Azmi. 2020, https://saintif.com/gus-azmi/.

Salas Tina, Hagi Julio; Kartika. "Representasi Identitas Santri (Analisis Semkotika Model John Fiske Dalam Film Cahaya Cinta Pesantren)." Al-Mishbah: Jurnal Ilmu Dakwah Dan Komunikasi, no. Vol 16 No 1 (2020), Komunitas Dosen Dakwah Institut Agama Islam Negeri (IAIN) Palu, 2020, hlm. 57-74, https://almishbahjurnal.com/ind ex.php/almishbah/article/view/179.

Sartika, Elita. "Analisis Isi Kualitatif Pesan Moral Dalam Film Berjudul 'Kita Versus Korupsi."” Jurnal Ilmu Komunikasi, vol. 2, no. 2, 2014, 
Komunike, Volume XII, No. 2 Desember 2020

hlm. 63-77.

Stemler, Steven E. "Content Analysis." Emerging Trends in the Social and Behavioral Sciences: An Interdisciplinary, Searchable, and Linkable Resource, Wiley Online Library, 2015, hlm. 1-14.
Veve Zulfikar. Profil Veve Zulfikar. 2020, http://vevezulfikar.com/?i=biogr afi/. 